* Mestranda em Direito pela Universidade de Santa Cruz do Sul (UNISC). Especialista em Direito Processual Civil pela Faculdade Futura (ICETEC). Bacharel em Direito pela Universidade de Santa Cruz do Sul (UNISC). Email: rafaela_611@hotmail.com

**Doutora em Direito pela Universidade do Vale do Rio dos Sinos (UNISINOS). Mestre em Desenvolvimento Regional pela Universidade de Santa Cruz do Sul (UNISC). Bacharel em Direito pela Universidade de Santa Cruz do Sul (UNISC). Email: fabiana@unisc.br

\section{MEdiação de CONFLitos: UMA ANÁlise A PARTIR dA EVOLUÇÃO HISTÓRICA E LEGISLATIVA DAS FORMAÇÕES FAMILIARES}

\author{
CONFLICT MEDIATION: AN ANALYSIS FROM THE HISTORICAL \\ AND LEGISLATIVE EVOLUTION OF FAMILY FORMATIONS
}

\section{Rafaela Peixoto Schaefer* Fabiana Marion Spengler**}

Como citar:SCHAEFER, Rafaela Peixoto. SPENGLER, Fabiana Marion. Mediação de conflitos: uma análise a partir da evolução histórica e legislativa das formações familiares. Scientia Iuris, Londrina, v. 24, n. 3, p. 31-49, nov. 2020. DOI: 10.5433/2178-8189.2020v24n3p31. ISSN: 2178-8189.

Resumo: As famílias são núcleos em constante transformação. As formações que antigamente recebiam demasiada influência religiosa, hodiernamente estabelecem-se pelos vínculos afetivos. Destarte, este artigo se propõe a analisar o instituto da família e a complexidade de suas relações, bem como, discutir uma proposta pacífica de gestão de controvérsias. A pesquisa foi norteada pela seguinte indagação: o instituto da mediação é um meio adequado de tratamento de conflitos oriundos de relações familiares? Ao final, verifica-se que a mediação é uma ferramenta consensual que possibilita a mudança do paradigma conflitivo e a harmonização social. O ponto de partida se dá pelo delineamento histórico e a abordagem conceitual e legislativa das formações familiares. Para tanto, empregou-se a técnica de pesquisa bibliográfica, a partir do método dedutivo que consiste em analisar premissas gerais relacionando-as aos particulares.

Palavras-chave: Conflito. Formações familiares. Mediação. Política pública.

Abstract: Families are constantly changing nuclei. The formations that once received too much religious influence, are today influenced by affective bonds. In this context, this paper analyzes families and the complexity of their relations, as well as discusses a peaceful proposal for managing controversies that arise within them. Considering this scenario, this research has the following research question: is mediation an appropriate means 
of conflict resolution for family relationships? In the end, this article verifies that mediation is a consensual tool that substitutes the current conflict paradigm, thusly, helping develop social harmonization. Furthermore, this study examines the history of family formations from a conceptual and legislative approach. In order to accomplish this, the bibliographic research technique was used, based on the deductive method that consists of analyzing general premises and relating them back to individuals.

Keywords: Conflicts. Family formations. Mediation. Public policy. 


\section{INTRODUÇÃO}

O tema a ser apresentado no presente trabalho discorre acerca das relações familiares e seus conflitos a partir da análise do contexto histórico e legislativo, haja vista a complexidade destas relações e a necessidade de um meio adequado para a gestão da controvérsia.

As famílias são grupos formados por pessoas que se unem a partir de vínculos afetivos e parentalidade. Mas nem sempre foi assim. No passado, as famílias eram constituídas com o objetivo de garantir a produção e a proteção do patrimônio. Neste contexto, o núcleo familiar era formado pelo homem, o chefe familiar; a esposa submissa e os filhos, que eram gerados para ajudar na produção familiar. Ainda, em algumas civilizações, o termo família já foi sinônimo de conjunto de escravos.

Diante de tantas evoluções e transformações das formações familiares e, consequentemente, da sociedade, trata-se de uma discussão pertinente, pois o Direito de Família é amplamente debatido e deve estar alinhado a essas demandas. Deste modo, a pesquisa foi norteada pela seguinte indagação: o instituto da mediação é um meio adequado de tratamento de conflitos oriundos de relações familiares? A hipótese apresentada, e ao final confirmada, é no sentido de que a mediação é uma ferramenta consensual que possibilita a mudança do paradigma conflitivo e a harmonização social. Para tanto, como metodologia, utilizou-se a técnica de pesquisa bibliográfica, a partir do método dedutivo que consiste em analisar premissas gerais relacionando-as aos particulares.

Destarte, o tópico inicial discorrerá sobre a evolução familiar, pautando os aspectos históricos e legislativos. A seguir serão tratados os novos formatos de família. Ao final, serão analisados os conflitos inerentes ao convívio familiar e o desafio da mediação enquanto política pública de pacificação.

\section{DA FAMÍLIA}

Ao longo da história, é possível identificar diversas formações familiares, que foram e são permeadas por fatores religiosos, políticos, sociais e econômicos. Logo, não é possível definir um único conceito de família aplicável a todas as épocas, pois este muda conforme o tempo, espaço e cultura (GAMA, 2008). Por esse motivo, muitos autores se debruçam sobre o tema, na tentativa de melhor contextualizá-lo.

Segundo Dias (2016), unir-se em grupos é um fato normal e necessário à natureza humana, essencial para a manutenção da sociedade e do Estado. Cada indivíduo tem seu papel dentro da família, o pai, a mãe, os filhos, contudo, não importa a sua função e sim pertencer a um grupamento familiar. É no seio familiar que aprendemos as primeiras lições, a transmissão de valores, o primeiro contato com o convívio social, no dizer de Dias (2016, p. 49), "[...] a família é o primeiro agente socializador do ser humano".

Neste viés, a família moderna é formada por membros que se unem pelo afeto ou parentesco, pelo matrimônio ou união sem casamento, e pelos filhos que podem ou não nascer destas relações. O parentesco é regulado por diversas legislações, assim, a família em conceito 
amplo, considera também os ascendentes, os descendentes e os colaterais do cônjuge, que são parentes por afinidade ou afins. (VENOSA, 2013).

No seio familiar as relações se desenvolvem baseadas nos princípios da solidariedade doméstica, da vida em comum e da cooperação recíproca. Significa dizer que a família contemporânea contempla elementos psicológicos e afetivos. Neste sentido, “[...] a família é uma construção social organizada através de regras culturalmente elaboradas que conformam modelos de comportamento humano, sendo fundamental o reconhecimento da estruturação psíquica na qual todos os integrantes ocupam um determinado lugar". (GAMA, 2008, p. 10):

$\mathrm{Na}$ antiguidade, as famílias eram denominadas patriarcais. Neste modelo, imperava a figura masculina, no qual o homem era a autoridade predominante sobre a esposa e os filhos, uma vez que a mulher casada era considerada relativamente incapaz. Assim, todas as decisões eram vinculadas ao genitor, não havendo possibilidade de interferência dos demais membros da família. (LÔBO, 2011).

Por muitos anos, esta tradição perdurou, sob forte influência religiosa, já que este autoritarismo era oriundo do casamento - ritual religioso, na época indissolúvel. Segundo Coulanges (1961), as famílias gregas e romanas mantinham crenças religiosas e adoração aos mortos, seus antepassados. Cada família adorava um deus e os cultos ocorriam em casa. O parentesco surgia do compartilhamento do fogo sagrado, contudo não existia parentesco com mulheres, e estas não participavam diretamente do culto, apenas através da figura do marido ou do pai.

O que une os membros da família antiga é algo mais poderoso que o nascimento, que o sentimento, que a força física: é a religião do fogo sagrado e dos antepassados. Essa religião faz com que a família forme um só corpo nesta e na outra vida. A família antiga é mais uma associação religiosa que uma associação natural. [...]. Sem dúvida, não foi a religião que criou a família, mas foi certamente a religião que lhe deu regras, resultando daí que a família antiga recebeu uma constituição muito diferente da que teria tido se houvesse sido constituída baseando-se apenas nos sentimentos naturais. (COULANGES, 1961, p. 35).

No Direito Romano, a família era caracterizada pelo poder paterno e pelos escravos, logo se difere largamente do conceito hodierno, repleto de sentimentos. Para os romanos, o termo família não se aplicava ao grupo familiar e seus membros, mas somente aos escravos. Nos ensinamentos de Engels (2009, p. 76, grifos no original): “Famulus quer dizer escravo doméstico e família é o conjunto de escravos pertencentes a um mesmo homem".

Para Aristóteles (1998, p. 51) “[...] a família é uma comunidade formada de acordo com a natureza para satisfazer as necessidades quotidianas". Nesse contexto, a relação entre os senhores e seus escravos era uma relação de dominação, que se justificava pela crença de que a escravidão era uma prática necessária, justa e inerente à própria natureza.

Seguindo a concepção aristotélica, a distinção entre homens livres e escravos quanto à condição de liberdade era verificável por meio da análise da anatomia humana, ou seja, Aristóteles "[...] atribuiu força física para aquele que irá desempenhar trabalhos pesados e presenteou os 
livres com uma postura altiva, habilitando-os para atividades que se relacionam tanto com o ato de fazer guerra quanto com a virtude de promover a paz" (WERMUTH; ZEIFERT, 2019, p. 243).

Lôbo (2011) explica que esse formato familiar era centrado no domínio do homem, com propósito na procriação. Nas palavras do autor "[...] foi a primeira forma de família fundada sobre condições não naturais, mas econômicas, resultando no triunfo da propriedade individual sobre a compropriedade espontânea primitiva" (LÔBO, 2011, p. 24). Logo, a família era constituída com objetivo de formar patrimônio, sem levar em conta a existência de afeto, por isso, não se falava em ruptura do vínculo matrimonial, pois este era fundado no patrimônio. Mais tarde, com a industrialização, a produção deixa de ser o elemento fundamental, dando espaço ao desenvolvimento de valores morais, afetivos e assistência recíproca. (VENOSA, 2013).

$\mathrm{Na}$ cidade antiga, com a expansão da religião, as famílias associavam-se em tribos, e, assim, deram início à formação das cidades. Todavia, as desigualdades eram marcantes na civilização antiga, pois as cidades eram divididas em classes de acordo com a religião. O pater era considerado cidadão e detinha o direito ao voto, ao contrário das mulheres, escravos, estrangeiros e clientes. O casamento era o ritual sagrado de inicialização de adoração aos deuses do marido, uma vez que a jovem abandonava o lar paterno e adotava outra religião, outros costumes. Isso porque, era permitido somente cultuar os deuses de um lar. (COULANGES, 1961).

O casamento, portanto, era obrigatório. Não tinha por finalidade o prazer; seu objetivo principal não era a união de duas criaturas que se convinham, e que desejavam unir-se para a felicidade ou sofrimentos da vida. O efeito do casamento, aos olhos da religião e das leis, era, unindo dois seres no mesmo culto doméstico, dar origem a um terceiro, apto a perpetuar esse culto. (COULANGES, 1961, p. 43).

Para Strauss, Gough e Spiro (1980) o casamento gerava uma divisão sexual do trabalho, sendo que cada cônjuge tinha suas tarefas determinadas, assim, às mulheres eram atribuídos os afazeres domésticos e aos homens, a guerra e a caça. Essa divisão "[...] não é mais do que um dispositivo para instituir um estado recíproco de dependência entre os sexos”, já que as tarefas designadas a um, ao outro eram proibidas. (STRAUSS; GOUGH; SPIRO, 1980, p. 30).

Atualmente, este cenário sofreu consideráveis modificações, pois a família deixou de ter como centro a figura paterna e passou a adotar um modelo de igualdade. As tarefas são distribuídas entre os componentes da família, buscando desenvolver suas aptidões e proporcionar o bem-estar de todos, abandonando a rigorosa divisão sexual do trabalho.

O Código Civil de 1916 reconhecia a família constituída através do matrimônio, com isso, continha em sua versão original uma restrita e discriminatória concepção de família. Esta legislação não permitia a dissolução do vínculo conjugal, fazia referências distintas entre seus membros, não acolhia as uniões sem casamento, nem seus frutos. Essas referências tinham caráter punitivo na tentativa de proteção do casamento. (DIAS, 2016).

Neste sentido, a sociedade contemporânea não se encontra mais apoiada na hierarquia e na autoridade masculina, mas sim no afeto e nas relações igualitárias. Com isso, se observa uma 
condição de respeito entre os integrantes do grupo. Para Dias (2016, p. 51, grifos no original): “[...] o formato hierárquico da família cedeu lugar à sua democratização, e as relações são muito mais de igualdade e de respeito mútuo. O traço fundamental é a lealdade”.

No mesmo viés leciona Lôbo (2011, p. 20): “[...] a afetividade, assim, desponta como elemento nuclear e definidor da união familiar, aproximando a instituição jurídica da instituição social. A afetividade é o triunfo da intimidade como valor, inclusive jurídico, da modernidade".

Ao Estado cabe regular o convívio social, proteger os indivíduos e intervir através de normas que devem ser respeitadas por todos, destarte, é possível afirmar que a maior incumbência estatal é a égide da instituição familiar. Nestes termos,

[...] a família constitui o alicerce mais sólido em que se assenta toda a organização social, estando a merecer, por isso, a proteção especial do Estado, como proclama o art. 226 da Constituição Federal, que a ela se refere como "base da sociedade". É natural, pois, que aquele queira protegê-la e fortalecê-la, estabelecendo normas de ordem pública, que não podem ser revogadas pela vontade dos particulares e determinando a participação do Ministério Público nos litígios que envolvem relações familiares. (GONÇALVES, 2014, p. 20, grifos no original).

No entanto, como a lei é posterior aos fatos, os modelos de famílias previstos juridicamente não atendem a realidade que se modifica constantemente, alterando, desta forma, a estrutura da família natural, “[...] que preexiste ao Estado e está acima do direito” (DIAS, 2016, p. 47). Por isso, da importância de o Estado estar atento a estas novas demandas, a fim de legislar de forma eficaz, seja por meio do Legislativo ou do Judiciário, como vem ocorrendo nos muitos anos.

A ampliação do papel feminino no contexto familiar, como também no mercado de trabalho, provocou relevantes alterações legislativas. Em 1962, quando foi editado o Estatuto da Mulher Casada, Lei 4.121, as mulheres deixaram de ser relativamente incapazes e tiveram reconhecida a propriedade dos bens adquiridos por meio de seu trabalho, e assim, passaram a ter os mesmos direitos do cônjuge. (DIAS, 2016).

Desta forma, as maiores inovações sobre a dissolução do casamento foram pouco a pouco inseridas na sociedade brasileira. Em 1977, entrou em vigor a Lei do Divórcio, Lei $n^{\circ}$ 6.515. A partir daí, foi regulamentada a separação judicial e o divórcio, extinguindo-se o desquite judicial, passando o casamento a ser uma instituição juridicamente dissolúvel. (DIAS, 2016).

Em 1988, a Constituição Federal rompe o vínculo entre a religião e o direito, com isso reforça a igualdade entre homens e mulheres, dilata o conceito de família, reconhece a união estável e a igualdade entre os filhos, sejam eles biológicos ou adotivos (DIAS, 2016). Nessa seara, explana Spengler (2018, p. 27):

[...] a pretensão constitucional é de proteger e resguardar todos os modelos de família, independentemente de sua constituição matrimonial ou extramatrimonial, igualar os cônjuges e os filhos, matrimoniais ou não, bem como prever a dissolubilidade do casamento. Pretende ainda garantir a dignidade da pessoa humana e a paternidade responsável, além do dever do Estado de prestar 
assistência a todas as espécies de famílias, garantindo direito e amparo a crianças e a adolescentes, assim como aos idosos.

A Carta Magna adotou os novos elementos das relações familiares, destacando-se, especialmente, os vínculos afetivos, que derrogaram diversos dispositivos da lei civilista vigente, provocando uma revolução no Direito de Família. Neste diapasão, a família socioafetiva é priorizada em homenagem ao princípio da dignidade da pessoa humana (GONÇALVES, 2014). Ou seja, além de reconhecer a pluralidade de núcleos familiares, a norma constitucional garante, a todos os membros do grupo familiar, proteção de forma igualitária. (SPENGLER, 2018).

Após o advento da Constituição Federal, foi editado o Código Civil em 2002, ainda com traços do código anterior, todavia, incorporou os direitos consagrados na Carta Magna. No que tange ao Direito de Família, constata-se a excessiva preocupação com a proteção do patrimônio. Sabe-se que as relações familiares, em sua maioria, envolvem interesses patrimoniais, contudo, quando estes tornam determinantes, a família deixa de exercer sua função enquanto local de afeto e pertencimento. Nessa linha, Lôbo (2011, p. 25) faz severa crítica ao código civilista:

[...] o anacronismo da legislação sobre família revelou-se em plenitude com o despontar dos novos paradigmas das entidades familiares. $\mathrm{O}$ advento do Código Civil de 2002 não pôs cobro ao descompasso da legislação, pois várias de suas normas estão fundadas nos paradigmas passados e em desarmonia com os princípios constitucionais referidos.

Do mesmo pensamento compartilha Dias (2016), ao alegar que o Código Civil já nasceu obsoleto, pois, não reconheceu as formações familiares existentes desde sempre, sendo assim, um código antigo com um texto novo. Como não poderia deixar de acontecer, a autora também destaca os avanços trazidos pela legislação civil. Diante da nova estrutura jurídica e social, foram abandonados expressões e preconceitos que causavam desconforto e discriminação, dentre elas a referência a homem e a mulher, a filiação, etc.

Merece menção, a exclusão da culpa e do instituto da separação, que se deu pela Emenda Constitucional 66/10, dando nova redação ao $\S 6^{\circ}$ do artigo 226 da Constituição Federal: "o casamento civil pode ser dissolvido pelo divórcio". Apesar de a separação continuar presente no texto civil, sua aplicação não reflete a evolução social e legislativa. Com isso, almeja-se que todos busquem a felicidade, pois a sociedade mudou, o conceito de família mudou. O casamento não deve sacrificar o bem-estar do casal, a ruptura deste vínculo é dolorosa, mas, muitas vezes, necessária. Por isso, a perquirição da culpa não tem espaço no ordenamento jurídico atual, já que fere a privacidade do casal. (DIAS, 2016).

Conclui Spengler (2018, p. 27): “Consequentemente, a Constituição de 1988 foi um marco na evolução do Direito de Família, que, além de receber os entendimentos já pacificados pelos tribunais, trouxe outros, de cunho inovador; deixou também a porta aberta para que novos avanços pudessem ocorrer".

Diante do exposto, a família evoluiu e transformou-se acompanhando as conquistas da 
humanidade, já que este instituto não é estático, novos valores são inseridos distanciando-se da rigidez de um passado remoto. A família, enfim, se fortalece na medida em que tem seus elementos edificadores baseados nos anseios sociais. Logo, o ordenamento jurídico deve andar em harmonia com a realidade, por esta razão a necessidade em reconhecer os diferentes modelos de família.

\section{AS FORMAÇÕES FAMILIARES}

O aumento das ações de divórcio, a inserção das mulheres do mercado de trabalho, entre outras mudanças sociais, são fatores que contribuíram para as alterações no núcleo familiar, originando novos formatos de família. A Constituição Federal, atendendo a necessidade de proteção dos indivíduos, ampliou os direitos das mulheres, crianças e idosos, e também, reconheceu os novos arranjos familiares.

A passagem da economia agrária à economia industrial atingiu irremediavelmente a família. A industrialização transforma drasticamente a composição da família, restringindo o número de nascimentos nos países mais desenvolvidos. A família deixa de ser uma unidade de produção na qual todos trabalhavam sob a autoridade de um chefe. $O$ homem vai para a fábrica e a mulher lança-se para o mercado de trabalho. No século XX, o papel da mulher transforma-se profundamente, com sensíveis efeitos no meio familiar. Na maioria das legislações, a mulher, não sem superar enormes resistências, alcança os mesmos direitos do marido. Com isso, transfigura-se a convivência entre pais e filhos. [...] Os conflitos sociais gerados pela nova posição social dos cônjuges, as pressões econômicas, a desatenção e o desgaste das religiões tradicionais fazem aumentar o número de divórcios. As uniões sem casamento, apesar de serem muito comuns em muitas civilizações do passado, passam a ser regularmente aceitas pela sociedade e pela legislação. A unidade familiar, sob o prisma social e jurídico, não mais tem como baluarte exclusivo o matrimônio. A nova família estrutura-se independentemente das núpcias. (VENOSA, 2013, p. 5-6).

Atualmente, a norma constitucional, em homenagem ao princípio do pluralismo das entidades familiares prevê os seguintes institutos: o casamento (artigo $226, \S 1^{\circ}$ e $2^{\circ}, \mathrm{CF}$ ), a união

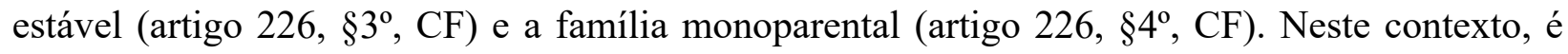
imperioso mencionar as famílias oriundas dos relacionamentos de pessoas do mesmo sexo, denominadas uniões homoafetivas. Este modelo foi inserido no ordenamento jurídico por meio de avanços jurisprudenciais quando o Supremo Tribunal de Justiça declarou, com caráter vinculante e eficácia erga omnes, sua existência jurídica. (DIAS, 2016).

O casamento por muitos anos foi caracterizado pela indissolubilidade, sob a influência religiosa, assim, somente se identificava a família se houvesse a celebração de tal ritual, a chamada família matrimonial, considerada a legítima. Sua função era a procriação, as relações afetivas aceitas nesta época, se justificavam para esse fim. Com isso, uma das possibilidades de anulação do casamento religioso, era a esterilidade de um dos cônjuges (DIAS, 2016).

Diferentemente, nos dias atuais, o amparo jurídico decorre dos laços afetivos que unem pessoas com propósitos em comum, sem considerar o sexo do par, sua cor ou sua condição 
financeira, assim afirma Lôbo (2011, p. 29): “[...] a família é sempre socioafetiva, em razão de ser grupo social considerado base da sociedade e unida na convivência afetiva". Isto ocorre porque, o casamento foi substituído pelo afeto, como expressamente traz o artigo $5^{\circ}$, inciso III, da Lei $\mathrm{n}^{\mathrm{o}}$ 11.340/06, Lei Maria da Penha, que considera família qualquer relação de afeto, haja vista a necessidade de amparar as uniões sem casamento (GAMA, 2008).

As mulheres conquistaram muitos direitos, como o surgimento de métodos contraceptivos, a possibilidade de romper o vínculo conjugal, a inserção no mercado de trabalho, política e economia. Com isso, puderam assumir outras responsabilidades, contribuir financeiramente para a manutenção do lar e participar das decisões familiares (MADALENO, 2001). Estes fatores contribuíram, juntamente, com o enfraquecimento da religião, para afastar a utopia da família idealizada e do casamento eterno (DIAS, 2016).

A união estável foi inserida no ordenamento jurídico pela Constituição Federal, porém, muitos casais viviam neste formato, por várias décadas sem respaldo legal. Explica Venosa (2013) que o legislador além de ser omisso quanto à norma regulamentadora, também negava as consequências jurídicas destes vínculos, desta forma, o filho fruto desta união não podia, sequer, buscar o reconhecimento do genitor, se este fosse casado. Segundo Dias (2016), isso acarretava em prejuízos ao filho, o qual era punido pela conduta do pai, que à época era considerada como criminosa.

Para Madaleno (2001, p. 1):

[...] a Carta Política de 1988 cedeu espaço, proteção e, portanto, conferiu status e identidade civil à realidade sociológica que encarna diversificadas modelagens de constituição, estrutura e de formatação familiar existentes nesse imenso País e assim procedeu ao retirar do porão de armazenagem das categorias excluídas, as famílias naturais, assim chamadas por terem nascido da informalidade de uma relação afetiva, outrora denominada de concubinato e modernamente rebatizada com a denominação jurídica de união estável.

O doutrinador Venosa (2013) diferencia os termos união estável e concubinato analisando seus elementos constitutivos. Na união estável, os conviventes partilham o mesmo teto ou não, como se casados fossem. Já o concubinato se refere às uniões do passado, antes chamados de concubinato impuro ou adulterino. Por se tratar de uma expressão depreciativa, a antiga denominação concubinos, foi substituída por companheiros. No posicionamento de Dias (2016, p. 415), a diferenciação trazida pelo Código Civil não é pertinente, pois evidencia que "[...] a pretensão é deixar as uniões 'espúrias' fora de qualquer reconhecimento e alijadas de direitos. Nitidamente punitiva a postura da lei, pois condena à invisibilidade e nega proteção jurídica às relações que desaprova". Ainda observa a autora, que a norma civil que veio para regular este novo - juridicamente - modelo familiar acabou impondo as regras do casamento aos indivíduos que não optaram por ele.

O Código Civil, no artigo 1.723, reproduz os requisitos constitucionais para o reconhecimento da união estável, quais sejam: a convivência duradoura, pública e contínua de um 
homem e uma mulher, com o objetivo de constituição de família. Tal artigo reforça que a família contemporânea é baseada no afeto, acolhendo a concepção eudemonista e afastando as exigências estatais e religiosas, prevalentes na família matrimonial, pois coloca como centro da relação, os indivíduos e não seu patrimônio. Lôbo (2011) conceitua esse fenômeno como repersonalização das relações civis ${ }^{1}$.

Nesse trilhar, Dias (2016) ressalta que a união estável tem origem nas relações em que há vínculos afetivos. $\mathrm{O}$ envolvimento mútuo entre as pessoas passa a ser identificado socialmente e o relacionamento é visto como uma unidade. Logo, esta unidade carece de tutela jurídica enquanto entidade, visto que a sua universalidade produz efeitos tanto de ordem pessoal quanto patrimonial.

Daí serem a vida em comum e a mútua assistência apontadas como seus elementos caracterizadores. Nada mais do que a prova da presença do enlaçamento de vida, do comprometimento recíproco. A exigência de notoriedade, continuidade e durabilidade da relação só serve como meio de comprovar a existência do relacionamento. Atentando a essa nova realidade o direito rotula a união de estável. (DIAS, 2016, p. 417).

A lei civilista ainda cuidou de estabelecer os deveres de lealdade, respeito, assistência, guarda, sustento e educação dos filhos. Nota-se que este dispositivo, além de atribuir critérios subjetivos, responsabiliza os conviventes, de forma igualitária, com relação à prole e a si próprios. Quanto às questões de natureza patrimonial, é facultada aos conviventes a elaboração de contrato de convivência, no qual é possível escolher o regime de bens, ou aplicar-se-á, no que couber, o regime de comunhão parcial de bens (VENOSA, 2013).

Ademais, a família deixou de ser sinônimo de casamento e filhos, pois, a ausência destes elementos não é mais essencial para a desconstituição como entidade familiar. Para Lôbo (2011, p. 173),

[...] por ser ato-fato jurídico (ou ato real), a união estável não necessita de qualquer manifestação de vontade para que produza seus jurídicos efeitos. Basta sua configuração fática, para que haja incidência das normas constitucionais e legais cogentes e supletivas e a relação fática converta-se em relação jurídica.

Com efeito, além de garantir a proteção e elencar algumas das formações familiares, a Constituição Federal promoveu a equiparação destas, visto que tanto o casamento como a união estável são reconhecidos e encontram-se sob a égide estatal. No que diz respeito ao Código Civil, importante observação traz Dias (2016) quanto ao equivocado tratamento dado à união estável pelo legislador civilista, o qual configura evidente violação ao princípio da igualdade. Em que pese à equiparação constitucional, a união estável aparece ao final do capítulo do livro de direito das famílias, disciplinada em três artigos (art. 1723 a 1726 do CC), trazendo apenas a legislação já

1 Conforme Lôbo (2011, p. 18): “[...] repersonalização das relações civis, que valoriza o interesse da pessoa humana mais do que suas relações patrimoniais. É a recusa da coisificação ou reificação da pessoa, para ressaltar sua dignidade. A família é o espaço por excelência da repersonalização do direito". 
existe, sob a justificativa de que o instituto foi constitucionalmente reconhecido durante a fase de elaboração do Código.

A norma constitucional também abrange o formato monoparental, formado por apenas um dos genitores e seus filhos. A exemplo da união estável, a família monoparental já existia em nossa sociedade. Dias (2016, p. 504) destaca a importância da proteção às famílias monoparentais observando sua fragilidade: “[...] as famílias monoparentais têm estrutura mais frágil. Quem vive sozinho com a prole acaba com encargos redobrados. Além dos cuidados com o lar e com os filhos, também necessita buscar meios de prover ao sustento da família”.

No entendimento de Lôbo (2011), a família monoparental é constituída por um dos genitores e seus filhos menores. Diversos fatores podem dar origem a esta formação, como a vontade ou desejo pessoal, o divórcio, a viuvez, a adoção de filho. Esta é a realidade de um terço das famílias brasileiras, em razão disto é indispensável à proteção estatal. As mulheres chefiam, na maioria dos casos, os lares monoparentais. Isso, por muito tempo foi associado ao fracasso da relação conjugal. Contudo, atualmente, é possível afirmar que este modelo familiar é uma escolha livre. (DIAS. 2016).

Oportuno esclarecer que o grupo formado por um membro que não seja parente, mas que detém a guarda de menores ou sendo os descendentes maiores, merece a mesma denominação. O elemento caracterizador "[...] é a transgeracionalidade, ou seja, haver diferença de gerações entre um de seus membros e os demais, sem que haja relacionamento de ordem sexual entre eles." (DIAS, 2016, p. 497, grifos no original).

$\mathrm{O}$ modelo monoparental difere-se do modelo anaparental, quanto à hierarquia entre gerações, já que neste último, inexiste. É o caso da família composta por irmãos ou pessoas parentes ou não, desde que mantenham convivência como entidade familiar.

Analisado os três modelos constitucionais de entidades familiares, é imperioso abordar os demais modelos que ilustram a sociedade. Outrossim, mesmo não sendo lembradas pelo legislador, estas estruturas também logram de égide constitucional. Assim, será apresentado um breve conceito destes formatos de família.

A família parental ou anaparental é formada por parentes consanguíneos ou não, que habitam no mesmo lar, e se unem, por exemplo, somando esforços para adquirir patrimônio. Exemplifica Dias (2016, p. 242):

[...] a convivência sob o mesmo teto durante anos, por exemplo, de duas irmãs que conjugam esforços para a formação do acervo patrimonial, constitui uma entidade familiar. [...] Ainda que inexista qualquer conotação de ordem sexual, a convivência identifica comunhão de esforços, cabendo aplicar, por analogia, as disposições que tratam do casamento e da união estável.

Diante das transformações sociais, novas estruturas familiares se formam, nas quais os casais após a separação encontram novos companheiros. Então, passam a constituir um novo núcleo, o casal, os filhos do outro relacionamento e os filhos em comum. Esse arranjo familiar ainda 
não possui uma denominação singular, por isso das diversas expressões - família multiparental, pluriparental, composta ou mosaico. Conforme Dias (2016, p. 243) são famílias que se formam por membros oriundos de relacionamentos anteriores, caracterizada pela: "[...] multiplicidade de vínculos, a ambiguidade dos compromissos e a interdependência [...]. É clássica expressão: os meus, os teus, os nossos".

Da mesma maneira, as relações entre pessoas do mesmo sexo, por muitos anos, foram ignoradas pela sociedade e excluídas do ordenamento jurídico, como forma de não aceitar sua existência, contudo, a omissão legislativa não implica na inexistência de direitos. $O$ termo homossexualismo perdeu o sufixo "ismo" que significa doença, e foi incorporado o sufixo "dade", que se refere a modo de ser. Assim, a homossexualidade é uma orientação sexual, uma forma de viver. O reconhecimento destas uniões somente ocorreu, em 2011, no Poder Judiciário, quando finalmente, o Supremo Tribunal de Justiça, utilizando-se de princípios hermenêuticos, às reconheceu como entidades familiares, a exemplo do que já havia acontecido na justiça gaúcha, em 2001. (DIAS, 2016).

Ainda sobre o tema, acrescenta a autora, em homenagem aos princípios constitucionais da liberdade, da igualdade e da dignidade da pessoa humana, todos os cidadãos são tutelados pelo manto da juridicidade. (DIAS, 2016). A Constituição Federal ao elencar as entidades familiares não esgotou suas formas, pois se trata de cláusula geral de inclusão, isto significa dizer que não é permitir desconsiderar qualquer entidade que atenda aos requisitos de afetividade, estabilidade e ostensibilidade. Neste viés, a proteção estatal deve se estender a todos e a todas as relações de afeto, sendo irrelevante a orientação sexual dos indivíduos. (LÔBO, 2011).

Assim, percebe-se que o núcleo familiar está em constante alteração, abandonando os antigos e rigorosos padrões sociais. Neste diapasão, merece cuidadosa análise o instituto da mediação, visto como meio adequado de tratamento de conflitos familiares, pois diante da complexidade destas interações, o bem a ser tutelado é o ser humano e suas relações.

\section{MEDIAÇÃO DE CONFLITOS FAMILIARES E O DESAFIO DO TRATAMENTO ADEQUADO}

A partir da análise dos diferentes formatos familiares, constata-se que a família é um sistema vivo, ou seja, assim como a sociedade, não é estática. Neste ambiente íntimo, pessoas com particularidades e desejos diferentes interagem diariamente, mesmo que afetivamente ligadas, suas relações podem gerar situações conflituosas. Estes conflitos possuem natureza específica e complexa, de maneira que o afeto é o principal elo entre seus membros. Logo, a família é constituída por pessoas, suas relações e seus conflitos. Neste contexto, se busca desenvolver a individualização de cada membro, bem como, o sentimento de pertinência. (CEZAR-FERREIRA, 2011).

A palavra conflito tem origem no antigo latim, sua raiz etimológica traduz a ideia de choque, contraposição de ideais, valores, armas. Desse modo, o conflito acontece quando forças dinâmicas reagem umas sobre as outras com hostilidade em razão de um objeto. No entendimento 
de Morais e Spengler (2012, p. 45) o conflito "[...] consiste em um enfretamento entre dois seres ou grupos da mesma espécie que manifestam, uns a respeito dos outros, uma intenção hostil, geralmente com relação a um direito".

Nada obstante, sob a ótica positiva, verifica-se a importância do conflito como meio de promover mudanças, sendo que tais divergências compõem uma interação intensa entre indivíduos, que refletem dentro e fora do grupo, como forma de manutenção da convivência social. Desta forma, é possível afirmar que o conflito possui aspectos tanto negativos como positivos, por isso, a necessidade de enfrentá-lo, não com o objetivo de eliminá-lo, mas, de oferecer o tratamento adequado. (SIMMEL, 1983). "Ciò sottolinea l'importanza dell'ambivalenza funzionale del conflitto e, analogamente, anche del Terzo. È possibile notare che il conflitto può, in base alle sue caratteristiche e a come viene gestito, può tanto dividere quanto unire un determinato gruppo sociale". (SPENGLER; MARTINI, 2019, p. 33).

No mesmo sentido, Sales (2003, p. 57) entende “[...] o conflito como algo necessário para o reconhecimento dessas diferenças e para o encontro de novos caminhos que viabilizem uma boa administração das controvérsias". Complementa Warat (2004, p. 61): os conflitos são "[...] uma forma de inclusão do outro na produção do novo: o conflito como outridade que permita administrar, com o outro, o diferente para produzir a diferença".

O conflito transforma os indivíduos, seja em sua relação um com o outro, ou na relação consigo mesmo, demonstrando que traz consequências desfiguradoras e purificadoras, enfraquecedoras ou fortalecedoras. Ainda, existem as condições para que o conflito aconteça, e as mudanças e adaptações interiores geram consequências para os envolvidos indiretamente e, muitas vezes, para o próprio grupo. (MORAIS; SPENGLER, 2012, p. 54).

Quando o convívio conjugal se torna impossível, ocorre o rompimento do vínculo familiar, logo, um dos cônjuges ou ambos optam pelo divórcio ou pela dissolução da união estável. Farkas (2003) explica que esta ruptura desencadeia um período de luto, que serve como ritual de aceitação da nova situação. Segundo ela, tanto a pessoa que decide pela separação quanto à outra parte sofre com o afastamento. As mudanças mesmo que desejadas, representam novos desafios e expectativas, já para quem a separação é imposta, surgem o ressentimento, a rejeição e a angústia de não pertencer mais a uma unidade. A terapeuta esclarece "[...] é essa a condição do luto da separação. Bem feito, ele representa a possibilidade de superação. No sentido criativo, da perda, uma condição fundamental para quem quer recomeçar de fato a vida” (FARKAS, 2003, p. 367). Já Pereira (2003, p. 363) acrescenta a “[...] separação conjugal, que fará a passagem de um estado civil para outro, apesar do sofrimento, traz consigo o mesmo sentido do casamento, ou seja, as pessoas se casam para serem felizes, e separam, também, à procura da felicidade".

Ocorre que, esta separação afeta, não só o casal, mas todos os membros do núcleo familiar, especialmente os filhos. É nesta fase que se exige a atenção dos pais a fim de tornar a crise conjugal menos traumática aos menores. Já que, mesmo separados, as atribuições de cada genitor permanecem, as responsabilidades e a hierarquia também. Nesta linha, Maldonado (2009, 
p. 54) declara: “[...] quando um homem e uma mulher se separam, é o casamento que acaba, não a família. Com o término do casamento, a família transita para um outro tipo de organização (dois lares uniparentais, ou uma família de três gerações quando o homem e/ou mulher voltam a morar com os pais)".

A complexidade dessas demandas sobrevém, pois, envolvem emoções, expectativas e mágoas. Estes sentimentos não surgem repentinamente, mas vêm se acumulando por falta de diálogo ou mal-entendidos, e gradativamente se intensificam. Diante da decisão pela separação, os filhos, salvo exceções, desenvolvem o sentimento de culpa pela desestruturação da família, o que potencializa os traumas decorrentes desta transformação no núcleo familiar. Assim sendo, quando a controvérsia ingressa no Poder Judiciário o que se busca não é a reaproximação do casal, mas uma conduta atenta e adequada para conduzir a separação de forma que não agrave os ressentimentos e possibilite o restabelecimento do diálogo, evitando que os conflitos gerem danos às partes mais frágeis da relação. Partindo desta perspectiva, as ações de litígios familiares necessitam de tratamento mais acolhedor, assentado na afetividade, no diálogo e na satisfação. (SPENGLER, 2018).

Por conseguinte, é salutar que tais demandas recebam tratamento adequado por meio de mecanismos consensuais que tratam não apenas o conflito ora exposto, mas também daqueles sentimentos oprimidos, que não encontram espaço e tempo no tradicional processo judicial. Visto que, tais conflitos não serão solucionados apenas com uma sentença judicial que declare ou constitua direitos, já que a origem do litígio se dá no seio familiar. (SPENGLER, 2018).

Segundo Cezar-Ferreira (2011, p. 57):

[...] a separação não envolve, tão somente, uma discussão quanto a direitos e deveres. Os efeitos psicoindividuais e psicossociais que a separação pode acarretar levam-nos a perceber que ela é mais que mero resultado de manifestação de vontade e/ou vontades. Os conflitos gerados na separação trazem questões de ordem emocional que aludem às relações entre o casal e entre pais e filhos, pois como se sabe, envolvem sentimentos afetivos, relacionais e psicológicos, antecedidos de sofrimento. Isso, sem dúvida, dificulta ao Judiciário no momento de elaboração de uma decisão que seja ao mesmo tempo satisfatória e eficaz aos interesses dos envolvidos.

Em consequência da complexidade das relações familiares e da necessidade de promover a harmonização entre aqueles que buscam o Judiciário para dirimir suas contendas, surge o instituto da mediação, método considerado o mais apropriado para a condução pacifica e acolhedora do conflito. "Por isso, não se pode perder de vista a importância dessa prática em uma sociedade cada vez mais complexa, plural e multifacetada, produtora de demandas que a cada dia superam-se qualitativa e quantitativamente." (SPENGLER, 2018, p. 62).

O Estado, detentor da função jurisdicional, atua como fomentador e pacificador dos conflitos sociais. A implementação de políticas públicas de tratamento de conflitos não apenas torna o Judiciário mais moderno como também mais humanizado, pois se aproxima do indivíduo e 
contribui para a construção de uma sociedade justa e igual. Nesta senda, o Direito enquanto uma ciência dinâmica deve se ajustar de acordo com os acontecimentos sociais, tendo em vista que seu eixo gravitacional não se limita à legislação, mas sim à própria sociedade. Por conseguinte, se a sociedade muda, a legislação deve ser adaptada (MUNIZ, 2006).

$\mathrm{Na}$ legislação brasileira, a política pública da mediação foi instituída pela Resolução 125/10 do Conselho Nacional de Justiça, que dispõe sobre a Política Judiciária Nacional de tratamento adequado dos conflitos de interesses no âmbito do Poder Judiciário. Posteriormente, o Código de Processo Civil, alterado pela Lei 13/105/2015, propõe os meios consensuais como medidas voluntárias, com o fim de incentivar a adoção das práticas autocompositivas por todos os operadores do Direito. Já o marco legal da mediação se deu pela edição da Lei 13.140, de 26 de junho de 2015, que dispõe sobre a mediação entre particulares como meio adequado de tratamento de controvérsias e sobre a composição de conflitos no âmbito da Administração Pública. A lei é composta por 48 artigos que orientam o procedimento de mediação judicial e extrajudicial.

As políticas públicas ${ }^{2}$ de pacificação social são medidas que promovem a mudança no paradigma da cultura do litígio, minimizam a conflitualidade e ampliam o acesso à justiça. Segundo Cappelletti e Garth $(1988$, p. 12) "[...] o acesso à justiça pode, portanto, ser encarado como o requisito fundamental - o mais básico dos direitos humanos - de um sistema jurídico moderno e igualitário que pretenda garantir, e não apenas proclamar os direitos de todos”. Desta feita, os benefícios da mediação e conciliação perpassam o núcleo envolvido e suas relações, pois contribuem para o desenvolvimento e harmonização social.

A mediação é um procedimento voluntário, ou seja, as partes não são obrigadas a permanecer ou firmar acordo, o qual não julgam profícuo. Da mesma forma, não se pode olvidar que o "[...] bom andamento e o êxito da mediação são alcançados quando ao final da discussão os envolvidos conseguem construir uma solução negociada, de consentimento mútuo, amenizando o problema existente, buscando uma solução". (MAFIO; MARTINS; COSTA, 2020, p. 153). Neste procedimento, participarão os conflitantes e um terceiro imparcial, denominado mediador, ao qual incumbe promover o diálogo e auxiliar na elaboração de uma resposta satisfatória para os envolvidos.

Nesta conjuntura, a figura do mediador é essencial para a manutenção da paz, pois seu "[...] ruolo non è soltanto quello di ammortizzatore di impatti, antagonismi e tensioni, ma anche quello di essere un intermediario per la comunicazione" (SPENGLER; MARTINI, 2019, p. 32). Tendo em vista que o fim da mediação é a retomada da comunicação estremecida, "“[...] o acordo pode ser um dos desfechos possíveis, mas, ainda que não ocorra, se o diálogo amistoso foi restabelecido a mediação poderá ser considerada exitosa." (SPENGLER, 2018, p. 65-66).

Assentado nos princípios da oralidade, informalidade, confidencialidade, autonomia das partes e imparcialidade do mediador; o procedimento mediado não segue um rito predefinido, ou seja, as etapas e técnicas são aplicadas considerando as peculiaridades do caso concreto. Com isso, o intuito é proporcionar às partes um ambiente seguro e acolhedor, para que estes se sintam

Sobre o tema é importante a leitura de SCHMIDT (2018). 
confortáveis para expor seus dilemas e se tornem capazes de administrar suas relações. (MORAIS; SPENGLER, 2012).

A mediação é uma proposta transformativa, pois se desenvolve considerando o conflito, as pessoas e os sentimentos envolvidos. Desenvolvida num cenário democrático, centra-se na participação ativa das partes, estimulando o empoderamento, a consciência e a responsabilização. Desta forma, além de uma ferramenta de enfrentamento de conflitos, é uma importante medida educativa, que busca promover o lugar para o outro e a compreensão do outro a partir do autoconhecimento. "A mediação mostra o conflito como uma confrontação construtiva, revitalizadora, o conflito como uma diferença energética, não prejudicial, como um potencial construtivo. A vida como um dever conflitivo que tem que ser vitalmente gerenciado." (WARAT, 2004, p. 62).

O exercício da empatia possibilita a ressignificação das relações interpessoais, bem como, desperta para o trocar de lentes, substituindo a visão autocentrada por uma visão compassiva. Para tanto, é imperioso "[...] admitir que há um vasto campo de opiniões contrárias que são simplificadas por meio do diálogo; e, sobretudo, reconhecer que cada sujeito compartilha emoções próprias às vezes similares, às vezes não -, com suas razões e justificativas; e, consequentemente, aceitar o outro como sujeito de direitos". Certamente, não é uma conduta de simples aplicação, mas uma condição primordial no tratamento consensual de conflitos. (STANGHERLIN; SPENGLER, 2018, p. 79).

Neste trilhar, a mudança de olhar diante das situações conflitivas acontece de forma ecológica (WARAT, 2004), pois a resposta alcançada por meio da vivência da mediação é construída a partir da realidade e da possibilidade das partes, e não como se dá no modelo tradicional de justiça, em que a resolução é produzida por meio de uma sentença prolatada por um terceiro distante do conflito.

No entender de Spengler (2018, p. 64) a mediação “[...] não é uma ciência e sim uma arte”. Em síntese, trata-se de uma medida educativa que propõe a transformação do cenário conflituoso, ao passo que afasta a adversidade e possibilita compreensão do outro, reconhecendo-o com alteridade. Com efeito, os benefícios deste meio consensual são imensuráveis, pois alcançam não apenas as famílias, mas também a comunidade como um todo. Deste modo, diante da diversidade e complexidade das relações familiares, a mediação revela seu potencial pacificador, na medida em que se mostra com um relevante instrumento na busca pela harmonização e pacificação social.

\section{CONCLUSÃO}

Ao longo dos anos, as famílias vêm experimentando diversas mudanças, desde seu conceito até as atuais formações. Os núcleos que antes eram constituídos com a função de procriar e preservar o patrimônio já não existe mais. A família hodierna une-se através de laços afetivos, acolhendo a concepção eudemonista, baseado na igualdade, no afeto e no respeito entre seus membros.

Seguindo essa meada, considerando as mudanças na forma de constituir a família, 
podemos afirmar que tão significativo quanto à valorização dos vínculos afetivos no ambiente familiar, foi a regulamentação da possibilidade de dissolver o vínculo marital. Inicialmente, foram previstos os institutos do desquite e da separação, com forte carga conservadora que determinava o cumprimento de alguns requisitos. Felizmente, diante de tantas transformações e evoluções, o Direito também evoluiu e o casamento passou a ser dissolvido pelo divórcio.

Cumpre destacar, que o divisor de águas da sociedade contemporânea foi a promulgação da Constituição Federal, em 1988. A Carta Magna, não só extinguiu a exigência de prazos que impediam a ruptura imediata do matrimônio, como também ampliou o conceito de família, reconhecendo as diferentes formações, todavia mesmo aquelas não previstas gozam de proteção constitucional. Ainda, igualou os direitos entre cônjuges e filhos, sejam aqueles que se uniram em matrimônio ou não, bem como os filhos oriundos destas relações ou não.

Verificou-se ainda, que os avanços sociais foram timidamente inseridos no ordenamento jurídico pelo Poder Legislativo e em alguns casos pelo Poder Judiciário, como podemos citar o reconhecimento das uniões homoafetivas. As diversas formações familiares encontram-se disciplinadas tanto na Constituição Federal, como no Código Civil e Código Processual Civil. Mesmo diante de tantas legislações que tratam especificamente dos direitos e garantias das famílias, o tema requer maior atenção devido ao cenário complexo, conflituosos e inclinado a constantes mudanças.

No tocante ao enfrentamento dos conflitos familiares, destaca-se o emprego das ferramentas consensuais, como a mediação, considerada o meio de tratamento mais adequado para dirimir as questões oriundas do ambiente familiar. Uma vez, que o método consensual oferece às partes um espaço de escuta e participação, o qual objetiva o restabelecimento da comunicação através de técnicas apropriadas para conduzir o procedimento de forma pacífica e promover um desfecho satisfatório.

Por fim, atendendo ao problema de pesquisa, constata-se que os efeitos da política pública da mediação vão além do tratamento do conflito instaurado. Tendo em vista que o foco do instituto são as pessoas e seus conflitos, a proposta da mediação não é extinguir os conflitos, mas que estes possam ser adequadamente administrados, a fim de preservar a comunicação. Especialmente, no núcleo familiar onde as demandas se desenvolvem em meio a sentimentos reprimidos, a mediação apresenta uma nova concepção de gestão de conflitos, na qual as divergências são vistas como oportunidades de manutenção pacífica das relações e de prevenção de futuros desentendimentos.

\section{REFERÊNCIAS}

ARISTÓTELES. Política. Edição Bilíngue. Lisboa: VEGA, 1998.

CAPPELLETTI, Mauro; GARTH, Bryant. Acesso à justiça. Trad. Ellen Gracie Northfleet. Porto Alegre: Sérgio Fabris Editor, 1988.

CEZAR-FERREIRA, Verônica A. da Motta. Família, separação e mediação: uma visão psicojurídica. 3. ed. Rio de Janeiro: Forense; São Paulo: Método, 2011. 
COULANGES, Fustel de. A cidade antiga. São Paulo: Américas S.A./EDAMERIS, 1961.

DIAS, Maria Berenice. Manual de direito das famílias. 4. ed. São Paulo: Revista dos Tribunais, 2016.

ENGELS, Friedrich. A origem da família, da propriedade privada e do estado. 3. ed. São Paulo: Escala, 2009.

FARKAS, Melanie. O luto de uma separação. In: GROENINGA, G. C.; PEREIRA, R. da C. Direito de família e psicanálise: rumo a uma nova epistemologia. Rio de Janeiro: Imago, 2003. p. 365-370.

GAMA, Guilherme Calmon Nogueira da. Princípios constitucionais de direito de família: guarda compartilhada à luz da lei $\mathbf{n}^{\mathbf{0}}$ 11.698/08: família, criança, adolescente e idoso. São Paulo: Atlas, 2008.

GONÇALVES, Carlos Roberto. Direito civil brasileiro: direito de família - de acordo com a Lei n. 12.874/2013. 11. ed. São Paulo: Saraiva, 2014.

LÔBO, Paulo. Direito civil: famílias. 4. ed. São Paulo: Saraiva, 2011.

MADALENO, Rolf. Direito de Família Constituição e Constatação. [2001?]. Disponível em: $<$ http://www.rolfmadaleno.com.br/novosite/conteudo.php?id=27>. Acesso em: 13 jul. 2020.

MAFIO, Chanauana de Azevedo Canci; MARTINS, Vera Sirlei; COSTA, Valesca Brasil. A mediação como política pública de resolução de conflitos nas relações de consumo. Revista Scientia Iuris, Londrina, v.24, n.2, p. 149-169, jul. 2020. Disponível em: <http://www.uel.br/ revistas/uel/index.php/iuris/article/view/41020>. Acesso em: 02 ago. 2020.

MALDONADO, Maria Tereza. As mutações da família contemporânea: novas questões, novos problemas. Rio de Janeiro: Nova Fronteira, 2009.

MORAIS, J. L. B. de; SPENGLER, F. M. Mediação e arbitragem: alternativas à jurisdição! Porto Alegre: Livraria do Advogado. 3. ed. rev. e ampl., 2012.

MUNIZ, Tânia Lobo. Mediação - um instrumento de pacificação social: educar para a paz.

Revista Scientia Iuris, Londrina, v. 10, p. 243-270, 2006. Disponível em: <http://www.uel. br/ revistas/uel/index.php/iuris/article/view/4134>. Acesso em: 10 jun. 2020.

SALES, Lilia Maia de Moraes. A família e os conflitos familiares - a mediação como alternativa. Revista Pensar, Fortaleza, v. 8, n. 8, p. 55-59, fev. 2003. Disponível em: $<$ http://www.publicadireito.com.br/artigos/?cod=bf0c0d36a5a3f240 >. Acesso em: 17 jun. 2020.

SCHMIDT, João Pedro. Para estudar políticas públicas: aspectos conceituais, metodológicos e abordagens teóricas. Revista do Direito, v. 3, n. 56, p. 119-149, set/dez., 2018. Disponível em: $<$ https://online.unisc.br/seer/index.php/ direito/index>. Acesso em: 02 jhn. 2020.

SIMMEL, George. A natureza sociológica do conflito, in Moraes Filho, Evaristo (org.). São 
Paulo, Ática, 1983.

SPENGLER, Fabiana Marion. Mediação no direito familista e sucessório. Santa Cruz do Sul: Essere nel Mondo, 2018.

SPENGLER, F. M. Spengler; MARTINI, Sandra Regina. Il terzo e la fraternità nella configurazione triadica del conflitto social. In: ANASTASIA, Stefano; GONNELLA, Patrizio. I paradossi del diritto. Saggi in omaggio a Eligio Resta. Roma: Roma Tre-Press, 2019. p. 27-36.

STANGHERLIN, Camila; SPENGLER, Fabiana Marion. A comunidade enquanto local propício ao exercício da empatia: políticas públicas para as soluções extrajudiciais de conflitos em âmbito comunitário. Revista Scientia Iuris, Londrina, v. 22, p. 74 - 87, nov. 2018. Disponível em: $<$ http://www.uel.br/seer/index.php/iuris/article/view/30726>. Acesso em: 29 jun. 2020.

STRAUSS, L.; GOUGH, K.; SPIRO, M. A família: origem e evolução. Porto Alegre: Villa Martha, 1980.

VENOSA, Sílvio de Salvo. Direito civil: direito de família. 13. ed. São Paulo: Atlas, 2013.

WARAT, Luis Alberto. Surfando na pororoca: o ofício do mediador. Florianópolis: Fundação Boiteux, 2004.

WERMUTH, M. Â. D.; ZEIFERT, A. P. B. O conflito como condição humana? Os limites da ação e as consequências para a convivência pacífica. Revista Videre, Dourados, MS, v. 11, n. 21, jan./jun. 2019. Disponível em: < http://ojs.ufgd.edu.br/index.php/videre/article/view/ 10186>. Acesso em: 04 jan. 2020.

Como citar:SCHAEFER, Rafaela Peixoto. SPENGLER, Fabiana Marion. Mediação de conflitos: uma análise a partir da evolução histórica e legislativa das formações familiares. Scientia Iuris, Londrina, v. 24, n. 3, p. 31-49, nov. 2020. DOI: 10.5433/2178-8189.2020v24n2p31. ISSN: $2178-$ 8189.

Recebido em: 27/08/2020

Aprovado em: 14/10/2020 